\title{
IN VITRO ACTIVITY OF ORIGANUM VULGARE ESSENTIAL OIL AGAINST CANDIDA SPECIES
}

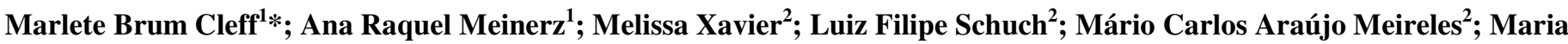 Regina Alves Rodrigues ${ }^{3}$; João Roberto Braga de Mello ${ }^{4}$}

${ }^{1}$ Programa de Pós-graduação em Ciências Veterinária, Faculdade Veterinária, Universidade Federal do Rio Grande do Sul, Porto Alegre, RS, Brasil; ${ }^{2}$ Departamento de Veterinária Preventiva, Faculdade Veterinária, Universidade Federal de Pelotas, Pelotas, RS, Brasil; ${ }^{3}$ Departamento de Química Orgânica, Instituto de Química, Universidade Federal de Pelotas, Pelotas, RS, Brasil; ${ }^{4}$ Departamento Farmacologia, Instituto de Ciências Básicas da Saúde, Universidade Federal do Rio Grande do Sul, Porto Alegre, RS, Brasil.

Submitted: May 12, 2008; Returned to authors for corrections: August 06, 2008; Approved: August 21, 2009.

\begin{abstract}
The aim of this study was to evaluate the in vitro activity of the essential oil extracted from Origanum vulgare against sixteen Candida species isolates. Standard strains tested comprised $C$. albicans (ATCC strains 44858, 4053, 18804 and 3691), C. parapsilosis (ATCC 22019), C. krusei (ATCC 34135), C. lusitaniae (ATCC 34449) and C. dubliniensis (ATCC MY646). Six Candida albicans isolates from the vaginal mucous membrane of female dogs, one isolate from the cutaneous tegument of a dog and one isolate of a capuchin monkey were tested in parallel. A broth microdilution technique (CLSI) was used,

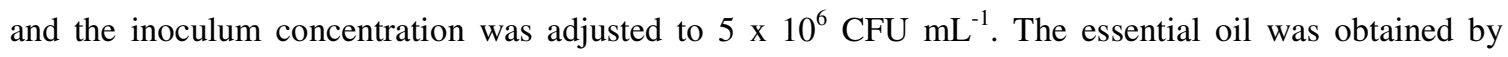
hydrodistillation in a Clevenger apparatus and analyzed by gas chromatography. Susceptibility was expressed as Minimal Inhibitory Concentration (MIC) and Minimal Fungicidal Concentration (MFC). All isolates tested in vitro were sensitive to $O$. vulgare essential oil. The chromatographic analysis revealed that the main compounds present in the essential oil were 4-terpineol (47.95\%), carvacrol (9.42\%), thymol $(8.42 \%)$ and $\square$-terpineol (7.57\%). C. albicans isolates obtained from animal mucous membranes exhibited MIC and MFC values of $2.72 \mu \mathrm{L} \mathrm{mL}^{-1}$ and $5 \mu \mathrm{LL}^{-1}$, respectively. MIC and MFC values for C. albicans standard strains were $2.97 \mu \mathrm{L} \mathrm{mL}^{-1}$ and $3.54 \mu \mathrm{L} \mathrm{mL}^{-1}$, respectively. The MIC and MFC for non-albicans species were $2.10 \mu \mathrm{L} \mathrm{mL}^{-1}$ and $2.97 \mu \mathrm{L} \mathrm{mL}^{-1}$, respectively. The antifungal activity of $O$. vulgare essential oil against Candida spp. observed in vitro suggests its administration may represent an alternative treatment for candidiasis.
\end{abstract}

Key words: Candida, Origanum vulgare, essential oil, in vitro.

\footnotetext{
*Corresponding Author. Mailing address: Rua xavier Ferreira nº.618, Porto. Pelotas, RS, Brasil.; Tel.: (053) 3225.62.18/8401.6218.; Email: emebrum@bol.com.br
} 


\section{INTRODUCTION}

Candidiasis is a mycosis caused by different Candida species, which can promote superficial and systemic opportunist diseases around the world $(8,13,19,20)$. The presence of geriatric domestic animals and immunosuppressed patients, who are more susceptible to fungal infections, has increased the incidence of candidiasis $(8,18,20)$. The increasing clinical importance of mycoses in veterinary medicine in addition to the emergence of more severe presentations prompts to the development of new diagnostic procedures and treatments $(11,13,18,19)$.

Most antifungals currently available for the treatment of different clinical forms of this disease have limitations that hinder their use, which makes the search for safe, efficient antimycotic products or molecules necessary $(3,11,15,24$, 25).

In this context, research involving substances obtained from plants, especially from members of the Lamiaceae family such as Origanum vulgare, show promise. Several species of the genus Origanum have carvacrol and thymol (phenolic monoterpenes) among their main constituents; these are accompanied by other compounds such as $\rho$-cimene, $\square$ terpinolene, $\square$-terpinene, $\alpha$-terpineol, linalool, 4-terpinol, germacrene-D and $\alpha$-pinene, which are present in lower concentrations and also show antimicrobial activity $(1,2,4$, $5,11,12,14,21,22,23,29)$.

Oregano has antioxidant properties and exhibits antimicrobial activity against bacteria and fungi (1, 2, 5, 6, 9, $14,17)$. Some studies suggest that oregano exerts a therapeutic effect when administered to rats experimentally infected with Trichophyton rubrum (1). The antifungal activity of oregano essential oil against some species of Aspergillus such as $A$. parasiticus, A. niger, A. flavus and A. ochraceus was demonstrated in studies where it was shown to inhibit growth and aflatoxin production $(4,10)$. The effects of oregano essential oil on yeasts of medical importance such as Candida albicans isolated from human patients have also been studied
(7, 11, 16). However, data concerning the impact of essential oils on yeasts of the genus Candida isolated from the vaginal mucous membrane of female dogs and other animals with a diagnosis of candidiasis are scarce to date.

The aim of the current investigation was to study the antimicrobial activities of Origanum vulgare essential oil on Candida species in order to evaluate its use as a therapy.

\section{MATERIALS AND METHODS}

\section{Plant material}

Oregano samples (dried leaves from Chile) were purchased from a commercial supplier (Torrenueva Vascos Ltda., Uruguay, tnueva@adinet.uy), which provided a botanical identification certificate.

The moisture content was determined to be $9.7 \mathrm{~g} / 100 \mathrm{~g}$ on a dry basis, and the yield of essential oil (EO) in raw material was $1.282 \mathrm{~mL}$ (mL EO/100g of oregano).

\section{Essential oil}

Dried oregano leaves were submitted to hydrodistillation for $4 \mathrm{~h}$ using a Clevenger apparatus modified according to Brazilian Pharmacopeia IV (1988). After extraction, the oil was dried in anhydrous sodium sulfate, filtered, concentrated under ultrapure $\mathrm{N}_{2}$ and stored in amber flasks at $4^{\circ} \mathrm{C}(30)$.

\section{Chemicals}

All chemicals (hexane, dichloromethane) were of analytical grade. Analytical standards ( $\alpha$-pinene, $\beta$-pinene, myrcene, $\alpha$-terpinene, $\mathrm{p}$-cymene, limonene, 1,8-cineole, $\gamma$ terpinene, terpinolene, linalool, 4-terpineol, $\alpha$-terpineol, thymol and carvacrol) were supplied by Sigma. RPMI 1640 medium was purchased from Gibco (Gibco BRL, Grand Island, NY, USA); Tween 80 was acquired from Sigma; Sabouraud dextrose agar was supplied by Oxoid (Basingstoke, UK); McFarland standard was purchased from bioMérieux (Marcy l'Etoile, France); 3-morpholinopropanesulfonic acid (MOPS) buffer and phosphate-buffered saline (PBS) were from Sigma. 


\section{Chromatographic analysis}

Origanum essential oil was analyzed in a gas chromatograph equipped with a flame ionization detector (GC/FID, model Schimadzu 17A). Chromatographic analysis was carried out in a chromatograph equipped with a DB-5 silica capillary column (methyl siloxane with 5\% phenyl groups; dimensions: $30 \mathrm{~m} \mathrm{x} 0.25 \mathrm{~mm} \varnothing, 0.25 \mu \mathrm{m}$ film thickness). Nitrogen was used as the carrier gas with a flow rate of $1.0 \mathrm{~mL} \mathrm{~min}^{-1}$ and a split ratio of 1:50. Both injector and detector temperatures were set to $280^{\circ} \mathrm{C}$. The column temperature was programmed to gradually increase from $40^{\circ} \mathrm{C}$ to $145^{\circ} \mathrm{C}$ at a rate of $2^{\circ} \mathrm{C} \mathrm{min}^{-1}$, rise to $280^{\circ} \mathrm{C}$ at a rate of $10^{\circ} \mathrm{C}$ $\min ^{-1}$, and remain at $280^{\circ} \mathrm{C}$ for $10 \mathrm{~min}$. An aliquot of oregano essential oil was dissolved in hexane at a concentration of $5,000 \mu \mathrm{g} \mathrm{L}^{-1} ; 0.5 \mu \mathrm{L}$ of this solution was injected into the system. The essential oil was analyzed in triplicate. Analytical standards were dissolved in hexane at a concentration of 100 $\mu \mathrm{g} \mathrm{L}^{-1}$ and subjected to same conditions used for oregano essential oil.

\section{Antimicrobial activity}

\section{Candida species isolates}

Six Candida albicans isolates from the vaginal mucous membrane of female dogs, one isolate from the cutaneous tegument of a dog and one isolate from the cutaneous tegument of a capuchin monkey (Cebus apella), all obtained in Pelotas, Rio Grande do Sul, Brazil, were tested. They were stored at Mycology Laboratory, School of Veterinary Medicine, at Federal University of Pelotas (UFPel). The eight standard strains tested were ATCC 44858, ATCC 4053, ATCC 18804 and ATCC 3691 (C. albicans), ATCC 22019 (C. parapsilosis), ATCC 34135 (C. krusei), ATCC 34449 (C. lusitaniae) and ATCC MY646 (C. dubliniensis), all supplied by Osvaldo Cruz Foundation (Fiocruz; Rio de Janeiro, Brazil).

\section{Inoculum preparation}

Fungal inoculums were prepared from overnight culture (24h) on Sabouraud dextrose agar (SDA). Colonies were directly suspended in saline to obtain turbidity comparable to that of the $0.5 \mathrm{McF}$ arland standards (approximately $1.5 \times 10^{6}$ $\mathrm{CFU} / \mathrm{ml})$.

These initial suspensions were diluted 1:50 with sterile physiological saline solution and further diluted 1:20 in RPMI 1640 medium, providing inoculum containing $1-5 \times 10^{3} \mathrm{CFU}$ $\mathrm{mL}^{-1}$. Inoculums were dispensed in microtiter plates (Becton Dickinson Labware, Franklin Lakes, NJ, USA) at $100 \mu \mathrm{L}$ per well.

\section{Susceptibility tests}

Isolated yeasts were tested using a broth microdilution method, which was performed according to Clinical and Laboratory Standards Institute (CLSI, formerly National Committee for Clinical Laboratory Standards, NCCLS) M27A2 reference method, with minor modifications. Tween 80 was added to RPMI 1640 medium at a final concentration $1 \%$ in order to disperse the essential oil.

Ten serial dilutions of oregano essential oil from stock solutions were prepared in RPMI 1640 medium containing Lglutamine, no bicarbonate and buffered with MOPS at pH 7.0. In order to determine the minimal inhibitory concentrations (MICs) of the yeasts, $100 \mu \mathrm{L}$ of each essential oil dilution were dispensed per well from columns 1 to 10 of the microtiter plates previously inoculated with the different yeast strains. Columns 11 and 12 contained positive controls (inoculum/medium) and negative controls (essential oil/medium), respectively. The plates were incubated under aerobic conditions at $35^{\circ} \mathrm{C}$ for $48 \mathrm{~h}$ with shaking. Susceptibility was expressed as minimal inhibitory concentration (MIC), which was defined as the lowest essential oil concentration able to inhibit fungal growth after $24 \mathrm{~h}$ of incubation in comparison to the positive control. To determine minimal fungicidal concentration (MFC) values, $10 \mu \mathrm{L}$ of the yeastcontaining suspensions were removed from each well, plated in dishes containing SDA and further incubated to allow detection of yeast proliferation.

\section{STATISTICAL ANALYSIS}

MICs and MFCs of different Candida isolates were 
compared through analysis of variance followed by comparison between geometric means using the Tukey's test with the statistical software package Statistix 6.0. P values $\leq 0.05$ were considered significant.

\section{RESULTS AND DISCUSSION}

C. albicans strains isolated from animal mucous membranes were sensitive to oregano essential oil, with an average MIC of $2.72 \mu \mathrm{L} \mathrm{mL} \mathrm{m}^{-1}$ and an average MFC of $5 \mu \mathrm{L}$ $\mathrm{mL}^{-1}$; whereas, average MIC and MFC values for standard strains were $2.97 \mu \mathrm{L} \mathrm{mL} \mathrm{m}^{-1}$ and $3.54 \mu \mathrm{L} \mathrm{mL}{ }^{-1}$, respectively. Average MIC and MFC values for non-albicans Candida strains were $2.10 \mu \mathrm{L} \mathrm{mL}^{-1}$ and of $2.97 \mu \mathrm{L} \mathrm{mL}^{-1}$, respectively (Table 1).

Table 1. Minimal inhibitory concentration (MIC) and minimal fungicidal concentration (MFC) values of Origanum vulgare essential oil on Candida spp.

\begin{tabular}{|c|c|c|c|c|}
\hline ISOLATES & $\begin{array}{c}* \mathrm{MIC} \\
\%\end{array}$ & $\begin{array}{c}* \mathbf{M I C} \\
\left(\mu \mathrm{L} \mathbf{m L}^{-1}\right)\end{array}$ & $\begin{array}{c}* \text { MFC } \\
(\%)\end{array}$ & $\begin{array}{l}* \mathrm{MFC} \\
\left(\mu \mathrm{L} \mathbf{m L}^{-1}\right)\end{array}$ \\
\hline C. albicans (mucous membrane, dog 1 ) & $0.25-1$ & 2.5 & $0.5-1$ & 5 \\
\hline C. albicans (mucous membrane, $\operatorname{dog} 2$ ) & $0.25-1$ & 2.5 & $0.5-1$ & 5 \\
\hline C. albicans (mucous membrane, dog 3 ) & $0.25-1$ & 2.5 & $0.5-1$ & 5 \\
\hline C. albicans (mucous membrane, dog 4) & $0.5-1$ & 5 & 1 & 10 \\
\hline C. albicans (mucous membrane, dog 5) & $0.5-1$ & 5 & $0.5-1$ & 5 \\
\hline C. albicans (mucous membrane, dog 6) & $0.12-1$ & 1.2 & $0.25-1$ & 2.5 \\
\hline C. albicans (skin, dog) & $0.25-1$ & 2.5 & $0.5-1$ & 5 \\
\hline C.albicans (skin, monkey) & $0.25-1$ & 2.5 & $0.5-1$ & 5 \\
\hline C. albicans (ATCC 44858) & $0.25-1$ & 2.5 & $0.25-1$ & 2.5 \\
\hline C. albicans (ATCC 4053) & $0.5-1$ & 5 & $0.5-1$ & 5 \\
\hline C. albicans (IOC 3691) & $0.25-1$ & 2.5 & $0.5-1$ & 5 \\
\hline C. albicans (ATCC 18804) & $0.25-1$ & 2.5 & $0.25-1$ & 2.5 \\
\hline C. dubliniensis (MY 646) & $0.25-1$ & 2.5 & $0.5-1$ & 5 \\
\hline C. parapsilosis (ATCC 22019) & $0.25-1$ & 2.5 & $0.25-1$ & 2.5 \\
\hline C. lusitanie (ATCC 34449) & $0.12-1$ & 1.2 & $0.12-1$ & 1.2 \\
\hline C. Krusei (ATCC 34135) & $0.25-1$ & 2.5 & $0.5-1$ & 5 \\
\hline
\end{tabular}

*MIC $=$ minimal inhibitory concentration; $\mathrm{CFM}=$ minimal fungicidal concentration

The results show differences in susceptibility to oregano essential oil between the fresh Candida isolates and standard strains, as well as between different Candida species, although these differences were not statistically significant (Fig. 1). Some studies have reported higher MIC values for traditional antifungals used against $C$. albicans (24), which demonstrates the occurrence of resistance to azole antifungals (15, 24, 25). These results are of clinical importance since $C$. albicans is responsible for the great majority of the infections in patients with recurrent candidiasis; in addition, C. albicans is the most frequently isolated species in cases of mucocutaneous candidiasis in small animals $(8,13,19)$ and is considered the most pathogenic species of the genus Candida $(7,11,24)$. Recent studies confirm the involvement of non-albicans Candida species in clinical cases of yeast infection in humans and animals $(18,20)$. In addition, the intrinsic resistance of Candida krusei to azole derivatives is known $(15,24)$. 


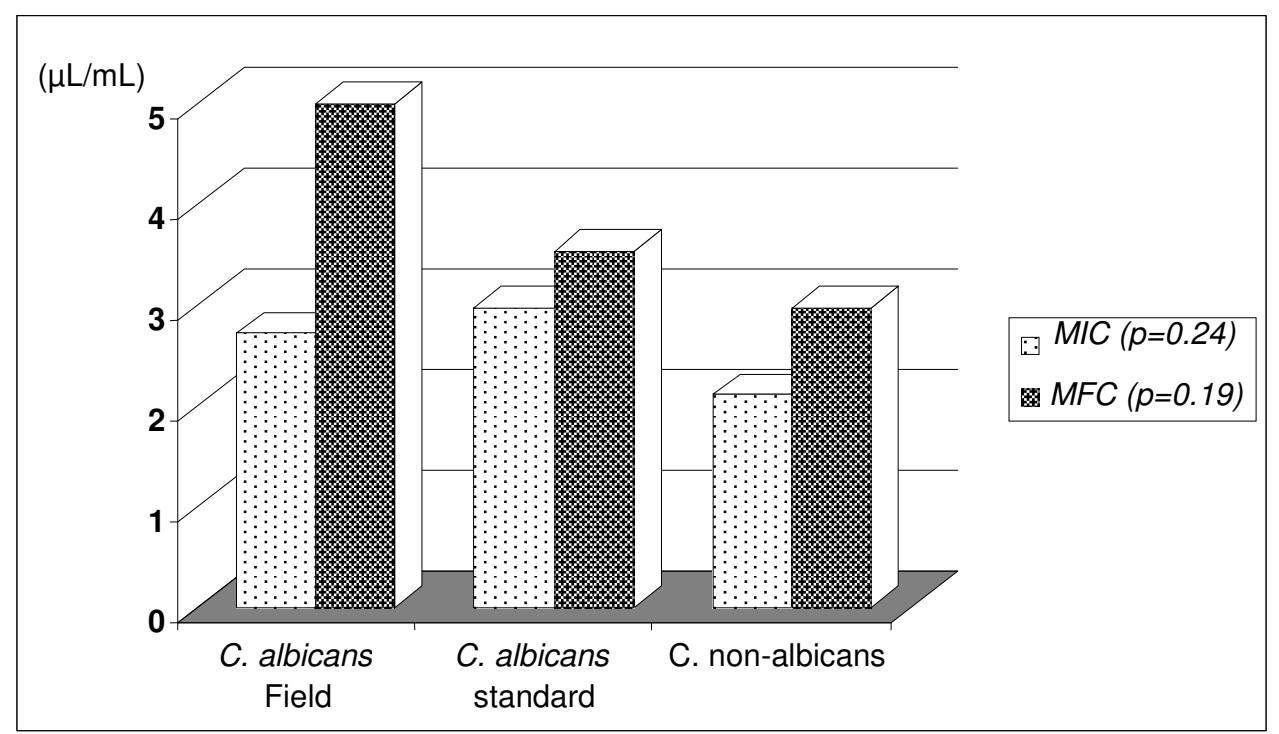

Figure 1. Minimal inhibitory concentration (MIC) and minimal fungicidal concentration (MFC) values of Origanum vulgare essential oil on $C$. albicans strains isolated from animal mucous membranes, standard Candida spp strains and non-albicans Candida strains.

Some authors have described the occurrence of clinical resistance and higher MIC values for some antifungals used against different non-albicans Candida species including $C$. lusitaniae e C. glabrata $(24,25)$. Aligiannis et al. (2) evaluated the MIC of the essential oils of two species of Origanum and found values between 0.28 and $1.27 \mathrm{mg} \mathrm{mL}^{-1}$ for bacteria and from 0.65 to $1.27 \mathrm{mg} \mathrm{mL}^{-1}$ for fungi, which are similar to the values found in our study $(7,16)$.

Chromatographic analysis of oregano essential oil revealed the presence of 4-terpineol, $\gamma$-terpinene, thymol and carvacrol among its main constituents. The concentration of phenolic monoterpenes was high as compared to those of the other compounds present in the oil (Table 2, Fig. 2). Some monoterpenes and sesquiterpenes could be responsible for the susceptibility of the isolates tested to this essential oil, since the antifungal activity of this oil has been attributed to thymol, carvacrol and eugenol $(6,7,14,29)$.

According to some studies, the composition, quality and content of essential oils present in plants are subject to great variation and are influenced by diverse factors such as the geographical and climatic conditions as well as the conditions used for culture, drying and storage $(3,9,12,17)$.

Inhibition of microorganisms by essential oils seems to rely on different mechanisms of action $(2,14,26,27,28)$. Toxic effects on membrane structure and function have been generally used to explain the antimicrobial action of essential oils and their monoterpenoid compounds $(12,26,27)$.

Some studies suggest that the antimicrobial action of essential oils can be a consequence of a negative effect on enzymes, including those involved in the production of energy and synthesis of structural components of the microorganism, in addition to destruction or inactivation of genetic material $(14,28)$.

Phenolic compounds present in essential oils may disturb membrane-embedded proteins and inhibit cellular respiration. Also, alterations in the ion transport processes of the cell membrane and modifications in the activity of calcium channels can cause an increase in cell permeability and consequent release of vital intracellular constituents (28). 
Table 2. Compounds identified in Origanum vulgare essential oil using chromatographic analysis (GC/FID).

\begin{tabular}{|c|c|c|c|c|}
\hline Peak & $\begin{array}{c}\text { Retention time } \\
(\mathrm{min})\end{array}$ & Compounds & MF & $\begin{array}{l}\text { C** } \\
(\%) \\
\end{array}$ \\
\hline 1 & 10.05 & $\alpha$-thujene & $\mathrm{C}_{10} \mathrm{H}_{16}$ & 0.25 \\
\hline 2 & 10.36 & $\alpha$-pinene* & $\mathrm{C}_{10} \mathrm{H}_{16}$ & nd \\
\hline 3 & 12.56 & sabinene & $\mathrm{C}_{10} \mathrm{H}_{16}$ & 0.33 \\
\hline 4 & 12.68 & $\beta$-pinene* & $\mathrm{C}_{10} \mathrm{H}_{16}$ & nd \\
\hline 5 & 13.75 & myrcene* & $\mathrm{C}_{10} \mathrm{H}_{16}$ & 0.18 \\
\hline 6 & 14.40 & $\alpha$-phellandrene & $\mathrm{C}_{10} \mathrm{H}_{16}$ & 2.47 \\
\hline 7 & 15.19 & $\alpha$-terpinene* & $\mathrm{C}_{10} \mathrm{H}_{16}$ & 2.83 \\
\hline 8 & 15.67 & p-cimene* & $\mathrm{C}_{10} \mathrm{H}_{14}$ & 0.71 \\
\hline 9 & 15.94 & limonene* & $\mathrm{C}_{10} \mathrm{H}_{16}$ & 3.60 \\
\hline 10 & 16.06 & 1.8-cineole* & $\mathrm{C}_{10} \mathrm{H}_{18} \mathrm{O}$ & 0.53 \\
\hline 11 & 16.75 & cis/trans $\beta$-ocimene & $\mathrm{C}_{10} \mathrm{H}_{16}$ & 0.08 \\
\hline 12 & 17.97 & $\gamma$-terpinene* & $\mathrm{C}_{10} \mathrm{H}_{16}$ & 4.86 \\
\hline 13 & 18.49 & trans sabinene hidrate & $\mathrm{C}_{10} \mathrm{H}_{18} \mathrm{O}$ & 0.07 \\
\hline 14 & 19.96 & terpinolene* & $\mathrm{C}_{10} \mathrm{H}_{16}$ & 1.69 \\
\hline 15 & 20.58 & cis sabinene hidrate & $\mathrm{C}_{10} \mathrm{H}_{18} \mathrm{O}$ & 0.08 \\
\hline 16 & 20.87 & Linalol* & $\mathrm{C}_{10} \mathrm{H}_{18} \mathrm{O}$ & 2.89 \\
\hline 17 & 22.18 & trans- $p$-menthenol & $\mathrm{C}_{10} \mathrm{H}_{18} \mathrm{O}$ & 0.12 \\
\hline 18 & 23.11 & cis- $p$-menthenol & $\mathrm{C}_{10} \mathrm{H}_{18} \mathrm{O}$ & 0.05 \\
\hline 19 & 25.20 & borneol & $\mathrm{C}_{10} \mathrm{H}_{18} \mathrm{O}$ & 0.27 \\
\hline 20 & 26.09 & 4-terpineol* & $\mathrm{C}_{10} \mathrm{H}_{18} \mathrm{O}$ & 47.95 \\
\hline 21 & 27.03 & $\alpha$-terpineol ${ }^{*}$ & $\mathrm{C}_{10} \mathrm{H}_{18} \mathrm{O}$ & 7.57 \\
\hline 22 & 27.43 & trans-piperitol & $\mathrm{C}_{10} \mathrm{H}_{18} \mathrm{O}$ & 0.35 \\
\hline 23 & 30.27 & methyl thymol eter & $\mathrm{C}_{11} \mathrm{H}_{16} \mathrm{O}$ & 0.10 \\
\hline 24 & 30.89 & methyl carvacrol eter & $\mathrm{C}_{11} \mathrm{H}_{16} \mathrm{O}$ & 0.71 \\
\hline 25 & 31.88 & geraniol/ nerol & $\mathrm{C}_{10} \mathrm{H}_{18} \mathrm{O}$ & 0.70 \\
\hline 26 & 34.41 & thymol* & $\mathrm{C}_{10} \mathrm{H}_{14} \mathrm{O}$ & 8.42 \\
\hline 27 & 35.00 & carvacrol* & $\mathrm{C}_{10} \mathrm{H}_{14} \mathrm{O}$ & 9.44 \\
\hline 28 & 40.54 & geranil/neril acetate & $\mathrm{C}_{12} \mathrm{H}_{20} \mathrm{O}_{2}$ & 0.20 \\
\hline 29 & 42.53 & $\beta$-caryophyllene & $\mathrm{C}_{15} \mathrm{H}_{32}$ & 2.92 \\
\hline 30 & 52.37 & spathulenol & $\mathrm{C}_{15} \mathrm{H}_{24} \mathrm{O}$ & 0.59 \\
\hline 31 & 52.67 & caryophylene oxide & $\mathrm{C}_{15} \mathrm{H}_{24} \mathrm{O}$ & 0.05 \\
\hline
\end{tabular}

* Compounds identified by comparison with standard compounds

** $\mathrm{C}(\%)=$ normalized peak areas using no correction factors

Other compounds were identified based on data from the literature $(6,23)$

nd $=$ not detected

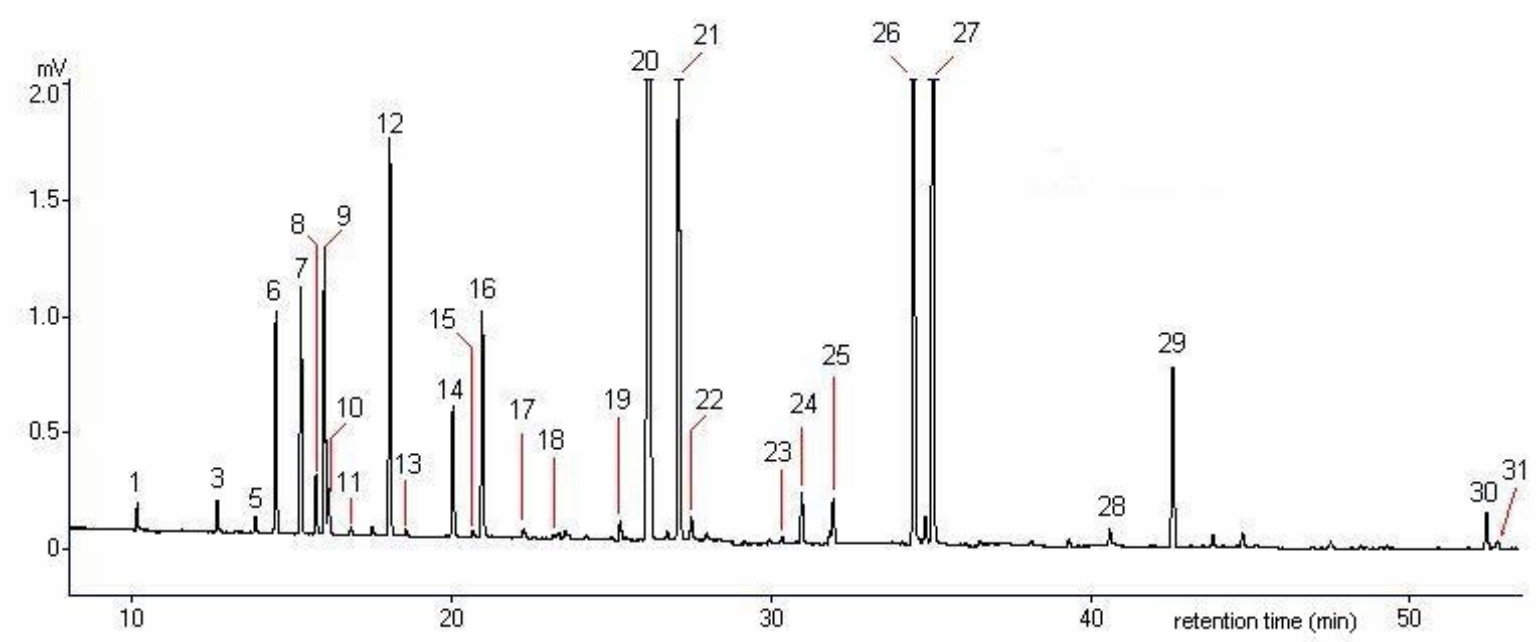

Figure 2. Chromatogram of oregano essential oil obtained by hydrodistillation. Terpineol (peak 20), carvacrol (peak 27), thymol (peak 26) and $\alpha$-terpineol (peak 21) are the main constituents. See table 2 for a description of the other peaks. 


\section{CONCLUSIONS}

Based on the results presented herein, it is possible to conclude that the essential oil extracted from $O$. vulgare may represent a good alternative for the treatment of candidiasis due to its appreciable antifungal action against Candida spp in vitro.

\section{ACKNOWLEDGMENTS}

This study was supported by Coordenação de Aperfeiçoamento de Pessoal de Nível Superior (CAPES), Conselho Nacional de Desenvolvimento Científico e Tecnológico (CNPq), Fundação de Amparo à pesquisa do Estado do Rio Grande do Sul (FAPERGS) and Programa de Pós-Graduação em Ciências Veterinárias da Universidade Federal do Rio Grande do Sul - UFRGS.

\section{REFERENCES}

1. Adam, K.; Sivropoulou, A.; Kokkini, S.; Lanaras, T.; Arsenakis, M. (1998). Antifungal activities of Origanum vulgare subsp. Hirusutum, Menthab spicata, Lavanula angustifólia and salvia fruticosa essential oils against human pathogenic fungi. J. Agricul Food Chem., 46, 1739-1745.

2. Aligiannis, N.; Kalpoutzakis, E.; Mitaku, S.; Chinou, I.B. (2001). Composition and antimicrobial activity of the essential oils of two Origanum species. J. Agric. Food Chem., 49, 4168-4170.

3. Arango, A.C.M.; Sánchez, J.G.B.; Galvis, L.A.B. (2004). Productos naturales con actividad antimicótica. Rev. Esp. Quimiot., 17, 325-331.

4. Basilico, M.Z.; Basilico, J.C. (1999). Inhibitory effects of some spice essential oils on Aspergillus ochraceus NRRL 3174 growth and achratoxin A production. Lett. Appl. Microbiol., 29, 238-241.

5. Baydarh, A.; Sagdiç, O.; Zkan, G. (2004). Antibacterial activity and composition of essential oils from Origanum, Thymbra and Satureja species with commercial importance in Turkey. Food Control., 15, 169172.

6. Busatta, C.; Mossi, A.J.; Rodrigues, M.R.A.; Cansian, R.L.; Oliveira, J.V. (2007). Evaluation of Origanum vulgare essential oil as antimicrobial agent in sausage. Braz. J. Microbiol., 38, 610-616.

7. Chami, N.; Chami, F.; Bennis, S.; Trouillas, J.; Remmal, A. (2004). Antifungal treatment with carvacrol and eugenol of oral candidiasis in immunosuppressd rats. The Braz. J. Infec. Dis., 8 (3), 217-226.

8. Cleff, M.B.; Silva, G.M.; Meinerz, A.R.M.; Madrid, I.M.; Martins, A.A.; Fonseca, A.O.; Nascente, P.S.; Meireles, M.C.A.; Mello J.R.B. (2007).
Infecção cutânea em cão por Candida albicans. Rev. Vet. Zoot. 14 (2), 164-168.

9. Dorman, H.J.D.; Surai, P.; Deans, S.G. (2000). In vitro antioxidant activity of a number of plant essential oils and phytoconstituents. $J$. Essenc. Oil Res., 12, 241-248.

10. Farag, R.S.; Daw, Z.Y.; Abo-Raya, S.H. (1989). Influence of some spice essential oils on Aspergillus parasiticus growth and production of aflatoxins in a synthetic medium. J. Food Science, 54, 74-76.

11. Giordani, R.; Regli, P.; Kaloustian, J.; Mikai, C.; Abou, L.; Portugal, H. (2004). Antifungal effect of Various Essential Oils against Candida albicans. Potentiation of Antifungal Action of Amphotericin B by Essential Oil from Thymus vulgaris. Phytot. Res., 18, 990-995.

12. Kokkini, S.; Karousou, R.; Vokou, D. (1994). Pattern of geographic variation of Origanum vulgare trichomes and essential oil content in Greece. Bioch System Ecol., 22, 517-528.

13. Lacaz, C.S.; Porto, E.; Martins, J.E.C.; Vaccari, E.M.; Melo, N.T. (2002). Tratado de Micologia Médica. 9ed., Sarvier, São Paulo, SP.

14. Lambert, R.J.W.; Skandamis, P.N.; Coote, P.J. (2001). A study of the minimum inhibitory concentration and mode of action of oregano esssencial oil, thymol and carvacrol. J Appl Microb., 91, 453-462.

15. Magill, S.S.; Shields C.; Sears, C.L.; Choti, M.; Merz, W.G. (2006). Triazole Cross-Resistance among Candida spp.: Case Report, Occurrence among Bloodstream Isolates, and Implications for Antifungal Therapy. J. Clin. Microbiol., 44, 529-535.

16. Manohar, V; Ingram, C.; Gray, J.; Talpur, N.A.; Bagghi, D.; Preuss, H.G. (2001). Antifungal activities of Origanum oil against Candida albicans. Molec. Cel. Bioch., 228, 111-117.

17. Milos, M.; Mastelic, J.; Jerkovic, I. (2000). Chemical composition and antioxidant effect of glycosidically bound volatile compounds from oregano (Origanum vulgare L. spp. hirtum). Food Chem., 71, 79-83.

18. Moretti, A.; Boncio, L.; Posteraro, B.; Mechelli, L.; Balducci, M. (2006). Co-cutaneous infection in a dog: pcr-reverse identification of $C$. tropicalis on skin biopsy. J. Mycol. Med., 16, 30-36.

19. Moretti, A.; Posteraro, B.; Boncio, L.; Mechelli, L.; Gasperis, E.; Agnetti, F.; Raspa, M. (2004). Diffuse cutaneous candidiasis in a dog. Diagnostic by PCR-REA. Rev. Iber. Micol., 21, 139-142.

20. Mueller, R.S.; Bettenay, S.V.; Shipstone, M. (2002). Cutaneous Candidiasis in a dog caused by Candida guilliermondii. Vet. Rec., 150, 728-730.

21. Rhyu, H.Y. (1979). Gas chromatographic characterization of oregano and other selected spices of the labiate family. J. Food Sc., 44, 1373-1378.

22. Rodrigues, M.R.A., Caramão, E.B., Santos, J.G. Dariva, C.; Oliveira, J.V. (2003). The effects of temperature and pressure on the characteristics of the extracts from high-pressure $\mathrm{CO}_{2}$ extraction of Majorana hortensis Moench. J. Agric. Food Chem., 51, 453-456.

23. Rodrigues, M.R.A., Krause, L.C., Caramão, E.B., Santos, J.G., Dariva, C.; Oliveira, J.V. (2004). Chemical composition and extraction yield of the extract of Origanum vulgare obtained from sub- and supercritical $\mathrm{CO}_{2}$. J. Agric. Food Chem., 52, 3042-3047. 
24. Sanglard, D.; Odds, F.C. (2002). Resistance of Candida species to antifungal agents: molecular mechanisms and clinical consequences. Lancet. Infect. Dis., 2, 73-85.

25. Santos Jr., I.D.; Souza, I.A.M.; Borges, R.G.; Souza, L.B.; Santana, W.J.; Coutinho, H.D.M. (2005). General traits of action, treatment and fungal resistance to fluconazol. Scientia Medica. 15, 189-197.

26. Sikkema, J.; Bont, J.A.M.; Poolman, B. (1994). Interactons of cyclic hydrocarbons with biological membranes. J. Biol. Chem., 269, 80228028.
27. Sikkema, J.; Bont, J.A.M.; Poolman, B. (1995). Mechanisms of membrane toxicity of hydrocarbons. Microbiol. Rev., 59, 201-222.

28. Trombetta, D.; Castelli, F.; Sarpietro, M.G.; Venuti, V.; Cristani, M.; Daniele, C.; Saija, A.; Mazzanti, G.; Bisignano, G. (2005). Mechanisms of Antibacterial action of three monoterpenes. Antim. Agents and Chemoth., 49, 2474-2478.

29. Wagner, K.H.; Elmadfa, I. (2003). Biological relevance of terpenoids. Overview focusing on mono- di- and tetraterpenes. Ann. Nutr. Metabol., 47, 95-106. 